\title{
Gender and citation in two LIS E-Journals: a comment
}

\author{
Peta Wellstead PhD \\ Research Fellow \\ Violence Research and Prevention Program \\ Key Centre for Ethics, Law, Justice and Governance \\ Griffith University \\ Australia \\ p.wellstead@griffith.edu.au
}

In LIBRES Vol 19, 1, 2010 Linsay Reece-Evans reported research which examined a bibliometric analysis of gender and citation in two LIS E-Journals: LIBRES and Information Research.

Reece-Evans makes the salient point that women outnumber men at a ratio of approximately 4:1 in the library and information science (LIS) field as a whole and 3:1 in academic librarianship. It is also noted that past studies suggest that male-authored LIS print journal articles outnumber female-authored articles both in number and in citations received. This is an important consideration in an environment where the amount of citations received can serve as an indication of status within the LIS profession and can affect chances for professional advancement.

Results of the reported study likewise suggest gendered affinity in citation and reference behaviour. Findings conclude that from 1995-2007 more men than women published articles in the two e-journals under review; that both men and women referenced more male-authored articles; that men referenced male-authored articles at a greater rate than women referenced female-authored articles; that articles by women received more citations overall; and that men cited articles by men at a greater rate than they cited articles by women. The study also found that female authorship was proportionately higher in the two LIS e-journals than in the three core LIS print journals reviewed for the study.

Reece-Evans suggests that the imbalance in citation and reference patterns is a result of gender influences on both male and female authors' choice of references, and that these gender influences also contribute to the amount of citations that authors receive.

I was awarded my doctorate in LIS at Curtin University in Western Australia in November 2009. Reading Reece-Evans' research provided some moments of reflection in terms of my own research behaviour, and the research base of the profession in Australia more generally. With these considerations in mind I thought the paper worthy of comment. Firstly, I cannot remember considering the gender of authors in research I cited in my $\mathrm{PhD}$ thesis, and secondly, it is often impossible to tell the gender from author data provided in papers. Is Reece-Evans male or female? The name is used by both males and females with a variety of spellings. The highest office holder in Australia, the Governor General, is named Quentin Bryce. Quentin is usually a male name, but the Governor General is a woman. And of course most of us are familiar with the tongue in cheek ballad of Johnny Cash, "A Boy Named Sue". My own name, Peta, the feminine of the more popular Peter, and is unknown in many countries. I routinely receive mail addressed to Mr. Pete Wellstead, people presuming that the "a" is a misspelt "e". Also, many journals use only initials for authors so gender can never be known.

It is statistically measurable and visually obvious that the LIS profession has a strong female bias in terms of numbers overall. But is this the whole picture? An examination of research behaviour within LIS in terms of publication and citation may have been enhanced by some data on the other measurements of the make-up of the profession. A review of age at point of entry; length of time spent in the profession; and a breakdown of the hours worked may have shed light on some of the findings presented. Some figures on the place of work on a gender 
basis may have also added considerably to the study. While the figures presented do indeed seem to suggest gender bias in authorship and citation in the two journals under review, an examination of the professional behaviour of women and men in LIS may have shed more light on the issue at hand.

Are women more likely to be working part-time and to have to sporadic professional and research careers? Possibly. Are women more likely to be working in practice based branches of the profession rather than in areas that generate high level research? Probably, because they can more easily work with a level of flexibility that reflects their needs during the parenting phase of their lives. In recent years women have become skilled at negotiating this flexibility and are more apt to do so than their male colleagues but it does present some dilemmas when compared with the benefits of a more linear pathway achievement of career goals and exposure in terms of gaining research grants and publication. Also, are research outputs impacted upon by women entering the profession later as second, or even third, career? Perhaps. Are there a significant number of career options for those who come to LIS research later in life due to sporadic career trajectories? Personal experience would suggest not.

It is important when conducting research into the LIS profession to recognise the lived reality of many who choose it. To separate the personal from the professional may lead us down pathways that come to dead ends. High quality LIS research is vital to maintain an evidence base in an information environment which is increasingly segmented. I am not totally convinced that it matters who is doing that research. In terms of perceived gender bias in publication bear in mind too, that peer review is blind and the gender of the writer is not known. In countries such as the USA and Australia, and many European countries 60 percent of university graduates are now women. In this new environment of graduate equity individuals will make choices about their career paths based on their own, often complex, circumstances. Editors, however, will make choices about publishing research based on only two criteria: the quality of the research and the quality of the writing.

Researchers too will make choices about citation based on two criteria: the quality of the research and the quality of the writing. They will also cite work which is relevant and appealing in terms of their own research interests. At the risk of being provocative, perhaps men are cited more often overall because they are doing better research, or writing about it in more effective ways. But then perhaps men get cited more often because they do more research earlier because their career paths are more linear which allows their research reputations to gain more leverage over time. During the ages of 25-45, when getting runs on the board in a research environment are crucial, more women work part-time. This flexibility may be the reason they choose the LIS profession in the first place. Similarly, if women are entering the profession later, while in pure numbers terms the gender bias is strong, it may not be as such in full- time equivalent terms for those crucial 25-45 years. All these complex factors will have impact on research outputs.

Women do need support to reach high level positions in LIS and to undertake high quality research. They also need to be mentored and supported to publish in the current publishing environment where 85 percent of submitted papers are rejected. Men in the profession also need this support. As a recent $\mathrm{PhD}$ graduate I can testify that the road to publication (which is an essential measure of research output to facilitate appointment to faculty positions) is fraught, painful and ego sapping. I am not sure that the gender of the writer has a great deal to do with that difficult pathway.

LIS is a profession dominated by women. If women are not reaching the pinnacle of career success (if that is what research publication and citation is?) it is somewhat disingenuous to suggest gender bias may be at fault. It may in fact have a little more to do with gender choice; where many women choose to invest professional and personal energy. In terms of work force planning and meeting the needs of the profession in an era of many challenges, both internal and external, this is a topic of utmost importance. Researchers such as Reece-Evans have much to offer the conversation about the personal and professional choices made by those who choose LIS as a career. 